\section{Cruz Novillo de Cine Retrospectiva}

\author{
Cruz Novillo of Cinema \\ Retrospective
}

La exposición Cruz Novillo de cine es el resultado de la colaboración entre Madrid Film Office, servicio público del Ayuntamiento de Madrid -que tiene como misión promocionar la ciudad como escenario idóneo de rodaje de producciones audiovisuales-, y DIMAD (Asociación y Fundación Diseño Madrid). Esta muestra, coproducida por ambas entidades, se celebró del 8 de noviembre al 17 de diciembre de 2019 en La Central de Diseño de Matadero Madrid, sede de DIMAD.

Desde los años sesenta, Cruz Novillo ha desarrollado también una línea de trabajo como diseñador de carteles de cine con el mismo afán renovador que en su obra de diseño corporativo. Se introduce en el ámbito del cine de la mano del director José Luis Borau, con quien coincide en la agencia de publicidad Clarín formando uno de los primeros dúos dibujante-copy de nuestro país. Será Borau quien le conecte con algunas de las figuras más destacadas del Nuevo Cine Español, que se fraguaría durante los años sesenta y setenta en torno a la Escuela Oficial de Cinematografía (EOC) y la persona que le recomendaría al productor Elías Querejeta, con quien desarrollaría una fructífera colaboración a lo largo de cuatro décadas. Durante todos estos años ha creado más de 80 carteles para películas de cineastas de la talla de Carlos Saura, Luis G. Berlanga, Víctor Erice, Jaime Chávarri, Ricardo Franco, Manuel Gutiérrez Aragón, Montxo Armendáriz o Fernando León de Aranoa, entre otros.

La exposición presenta la práctica totalidad de la cartelería cinematográfica de Cruz Novillo y se adentra en la dimensión más audiovisual de su obra como artista plástico, centrada en el concepto de Diafragma, donde trabaja con elementos cromáticos, fotográficos, tridimensionales y sonoros para jugar con todas las combinaciones posibles de sus variables.

Diferentes facetas de un diseñador y artista integral cuyos trabajos nos acercan al objetivo preferente que atraviesa el conjunto de su obra: la significancia y perdurabilidad.

\section{Soledad}

Hernández de la Rosa

Diseñadora, Presidenta de Dimad (Asociación Diseñadores de Madrid)

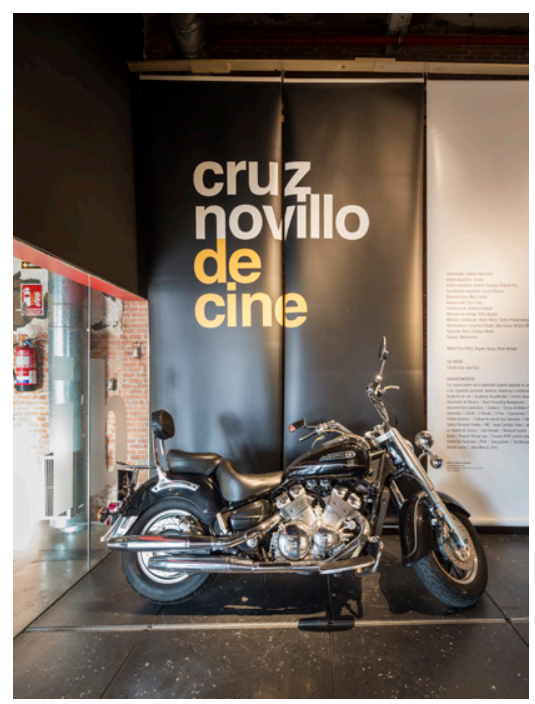

Fig. 1. Moto de Pepe Cruz Novillo. Yamaha Royal Star 1300. Medio de transporte habitual desde 1997. Fotografía Adrián Vázquez 





Fig. 3. Una pareja de asistentes a la exposición observando una de las producciones audiovisuales de Cruz Novillo. Fotografía Adrián Vázquez

Fig. 4. Desplegable de la exposición. Diseño de Roberto Turégano. Gráfica Aplicada Antonio Pita

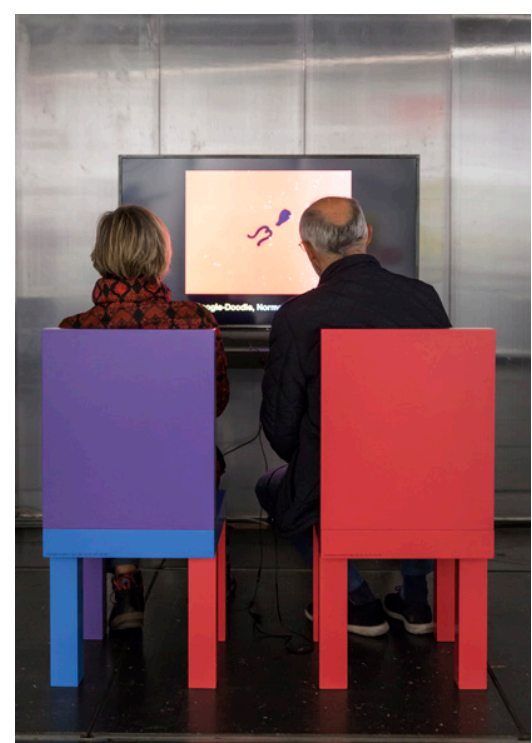

\section{Comisariado}

y discurso expositivo

Los ejes conceptuales sobre los que discurrió el discurso expositivo fueron la yuxtaposición de los siguientes aspectos:

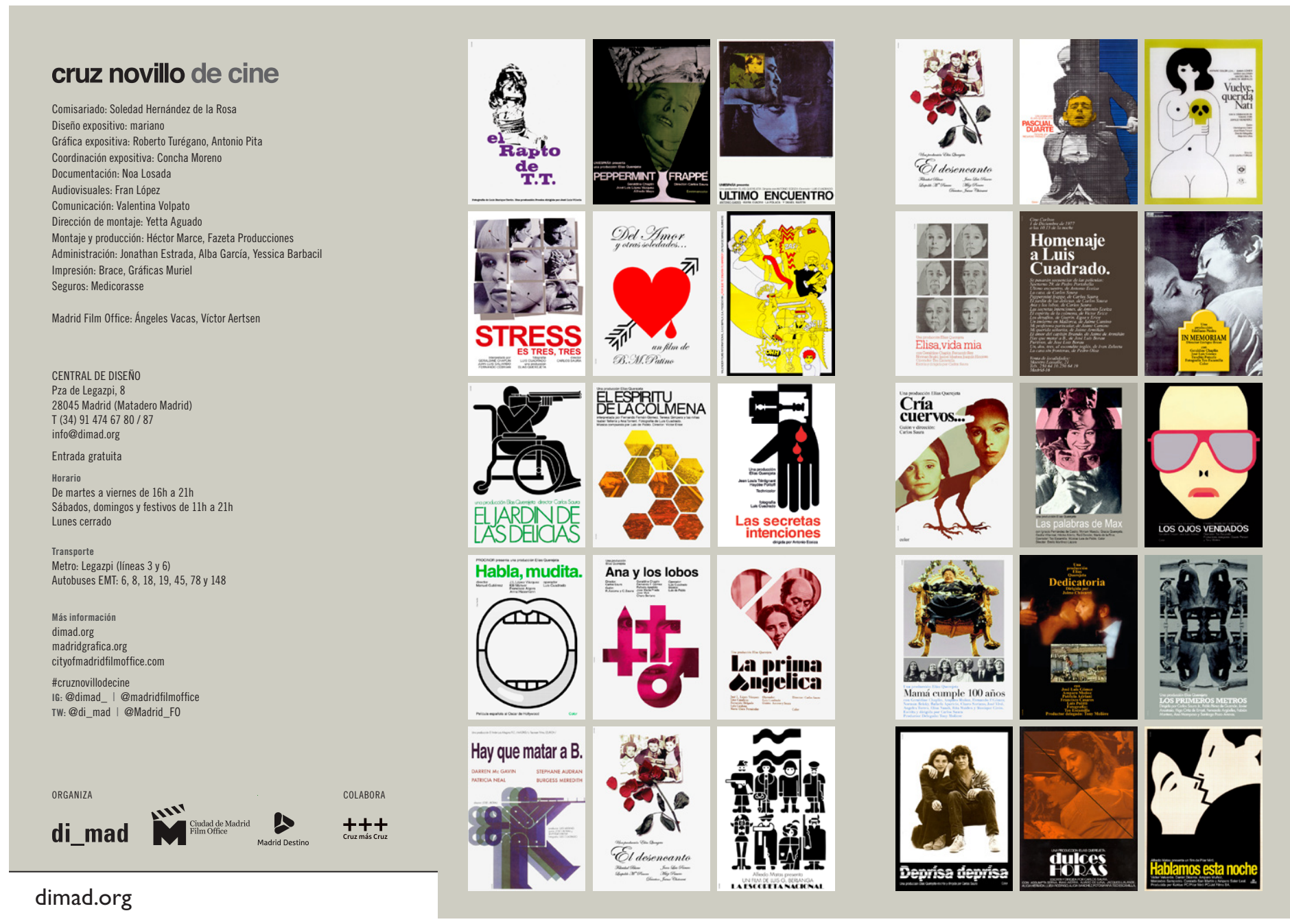


1. Descubrir al joven dibujante que se abre camino en el Madrid de finales de los 50 , sus inicios, sus influencias y mostrar aquellas facetas más íntimas de un diseñador que posteriormente se convertirá en referente y maestro de toda una generación de diseñadores. a través de los más de 80 carteles realizados para el cine, la relación de Pepe Cruz Novillo con Elías Querejeta y el nacimiento de lo que posteriormente se denominó el "Nuevo Cine Español”, sus protagonistas y su despliegue creativo desde años sesenta hasta la actualidad.
2. Dar a conocer,
3. Mostrar, con apenas unas pinceladas de su variado y polifacético recorrido, un Pepe Cruz Novillo donde no existe una estricta evolución formal, sino la expresión, ya sea mediante la pintura, la escultura o el diseño, de un artista integral con una clara coherencia y fidelidad interna.

\section{Describir la realidad socio cultural y po- lítica en la que Cruz Novillo desarrolló su trabajo junto a la de los producto- res, cineastas y resto de actores involucrados en la España de la época.}
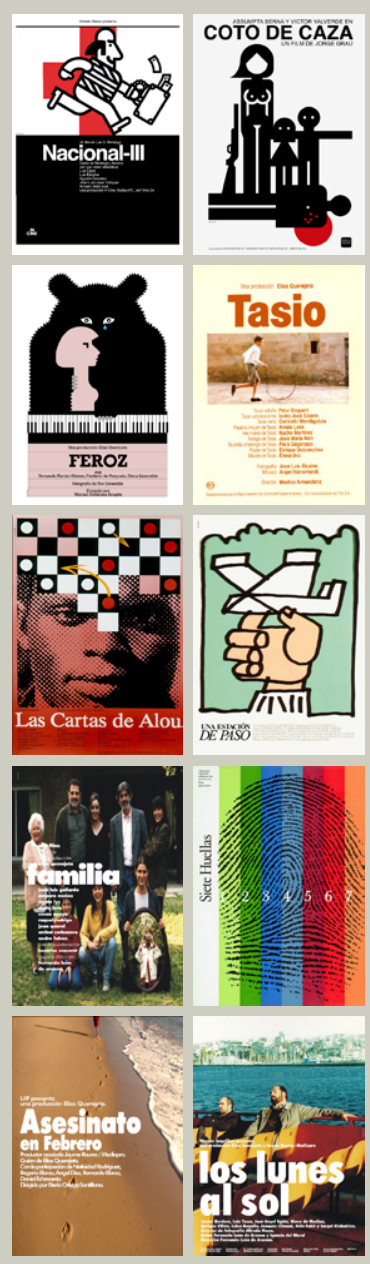
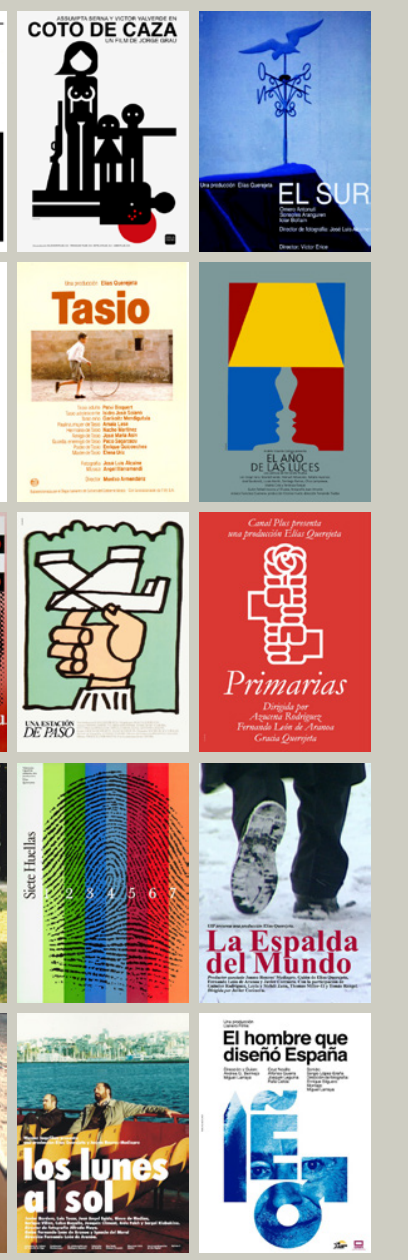

198 Deprisa deprisa. Carlos Saura + Dulces horas. Carlos Saura + Nacional III. Luis Garcia Berlang 1983 Coto de caza. Jorge Grau 1984 + Feroz. Manuel Gutiérrez Aragón
+ Tasio. Montxo Armendáriz Itres carteles 1985
+ Homenaje a Elias Querejeta. Varios autores 1986
+ El año de las luces. Fernando Trueba + 27 horas. Montxo Armendáriz 1989
+ Siete huellas. Varios autores [siete carteles]$$
1990
$$

1990
+ Las cartas de Alou. Montxo Armendáriz 1992 1992
+ Una estación de paso. Gracia Querejeta
[dos carteles] 1993 El aliento del diablo. Paco Lucio + Historias del Kronen. Montxo Armendáriz 1996 +El último viaje de Robert Rylands. Gracia Querejeta
+ Familia. Fernando León de Aranos 1997 1997 El partido del siglo. Varios autores 1998

+ Barrio. Fernando León de Arano Doñana. Memoria de un desastra Javier Corcuera
Euskadi en clave de futuro. Eterio Orteg + Primarias. Azucena Rodríguez, Fernando Leon, Gracia Querejeta
999. 1999
+ A través de Euskadi. Eterio Ortega mi lado Gracia Quereieta 2001 Asesinato en febrero. Eterio Ortega 2002 + Los lunes al sol. Fernando León de Arano La espalda del mundo. Javier Corcuer 2019
$+E I h$ + El hombre que diseñó España. Miguel Larraya



毒 | MADRID 
Fig. 5. Carpeta fotogramas Feria en Nueva York (9'). José Cárdenas y Pepe Cruz Novillo, con música de Luis de Pablo, 1963. Filmoteca Española


La exposición se divide en cinco grandes etapas por claras razones de eficiencia narrativa

\section{Etapa 1. Los Primeros Años}

Cruz Novillo nace en Cuenca en 1936. En 1956, coincidiendo con el nacimiento de RTVE, llega a Madrid para hacer el servicio militar y estudiar Derecho. En 1958 abandona los estudios y empieza a trabajar como dibujante en la agencia de publicidad Clarín, donde terminará siendo director creativo. A través de Clarín entra a colaborar en la Sociedad de Estudios de Diseño Industrial (SEDI) y se integra en el Grupo 13.
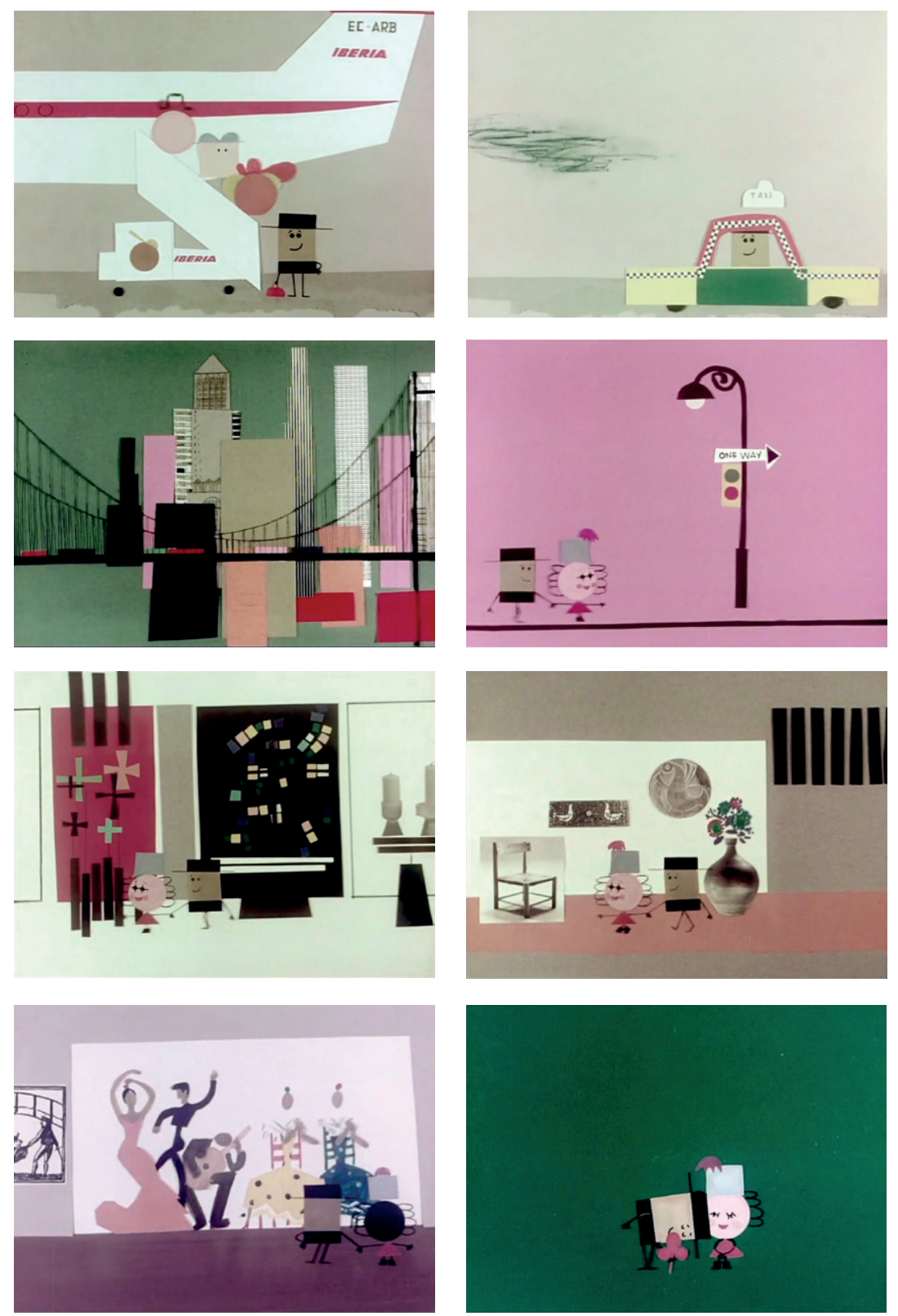


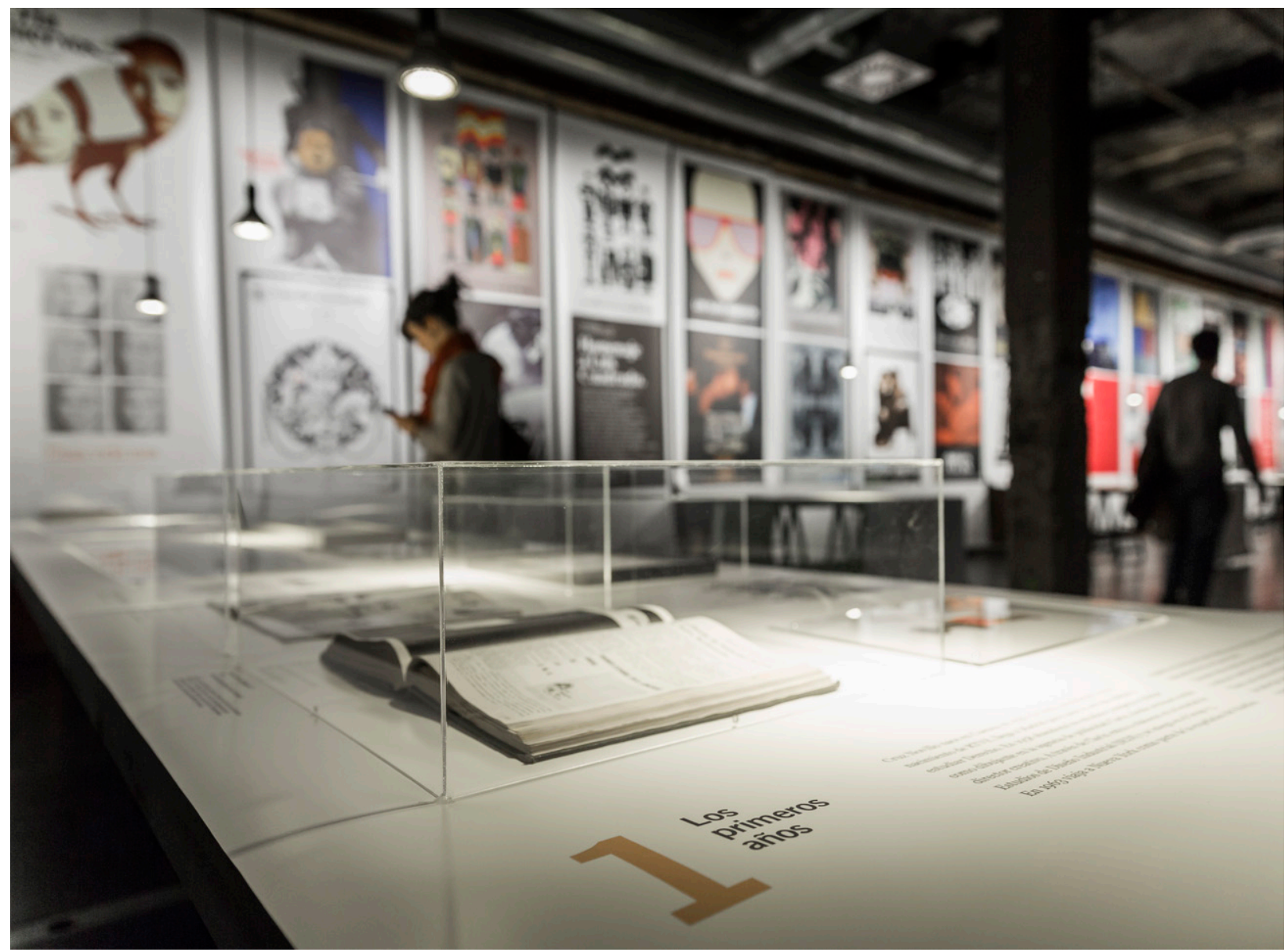

En 1963 viaja a Nueva York como parte de la expedición del Pabellón español en la feria mundial de Nueva York de 1964 y dirige el cortometraje de animación Feria en Nueva York.

Durante esta etapa hace sus primeras incursiones en el cine y realiza el cartel de El rapto de T.T. (1963), dirigida por José Luis Viloria, así como los títulos de crédito de Brandy (1963) y Crimen de doble filo (1964) de José Luis Borau. En 1965 se independiza y monta su estudio propio junto con Fernando Olmos.

\section{Etapa 2. El nuevo Cine Español}

José María García Escudero ocupa la Dirección General de Cinematografía entre 1962 y 1968, implanta un sistema objetivo de ayudas al cine e impulsa la escuela de cine. El hasta entonces Instituto de Investigaciones y Experiencia Cinematográficas (IIEC) pasa a denominarse Escuela Oficial de Cinematografía (EOC). Por sus aulas pasaría una nueva generación de cineastas comprometidos con la renovación de un cine español que refleje la realidad social de su época, como Luis García Berlanga, Juan Antonio Bardem, Carlos Saura, Basilio Martín Patino, José Luis Borau, Manuel Summers, Antonio Eceiza o Víctor Erice, entre otros. Esta generación de cineastas pasó a denominarse «El Nuevo Cine Español».
Figs. 6-8. Primeros planos obra gráfica Cruz Novillo. Fotografías Adrían Vázquez
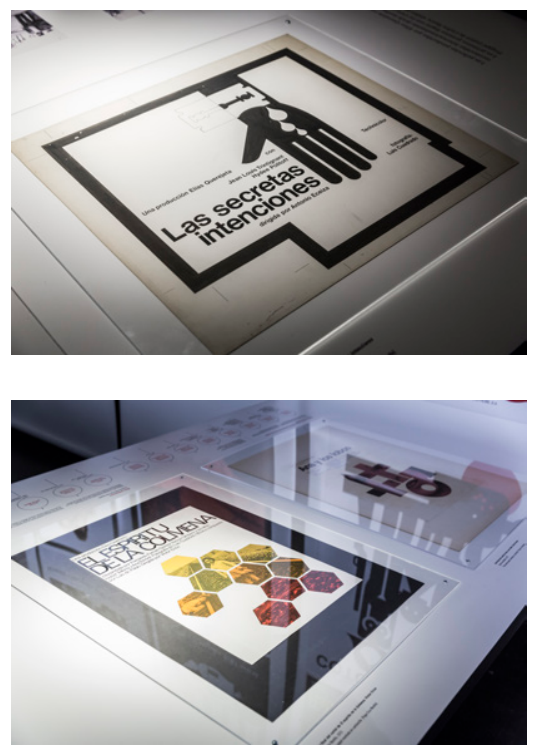


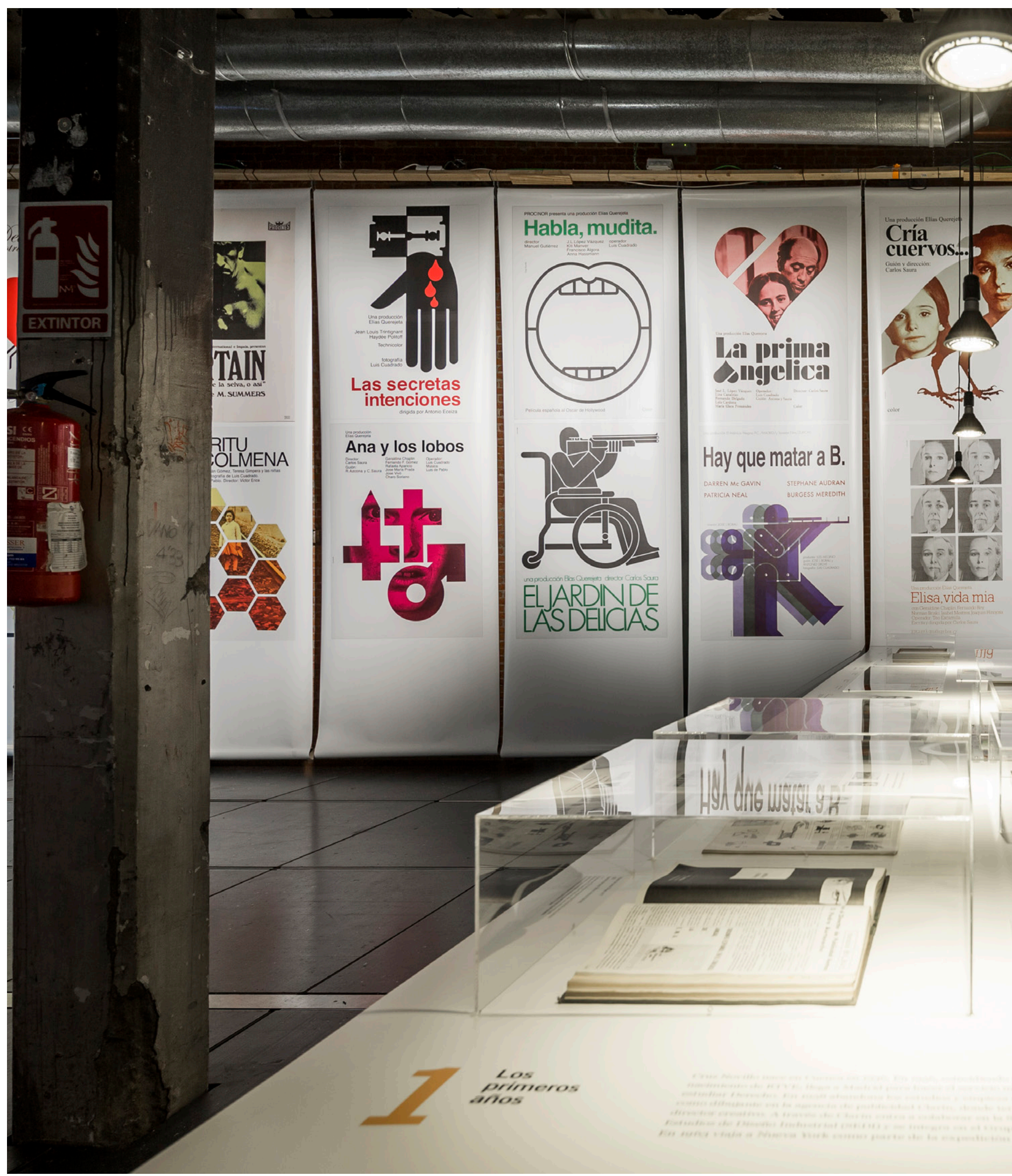




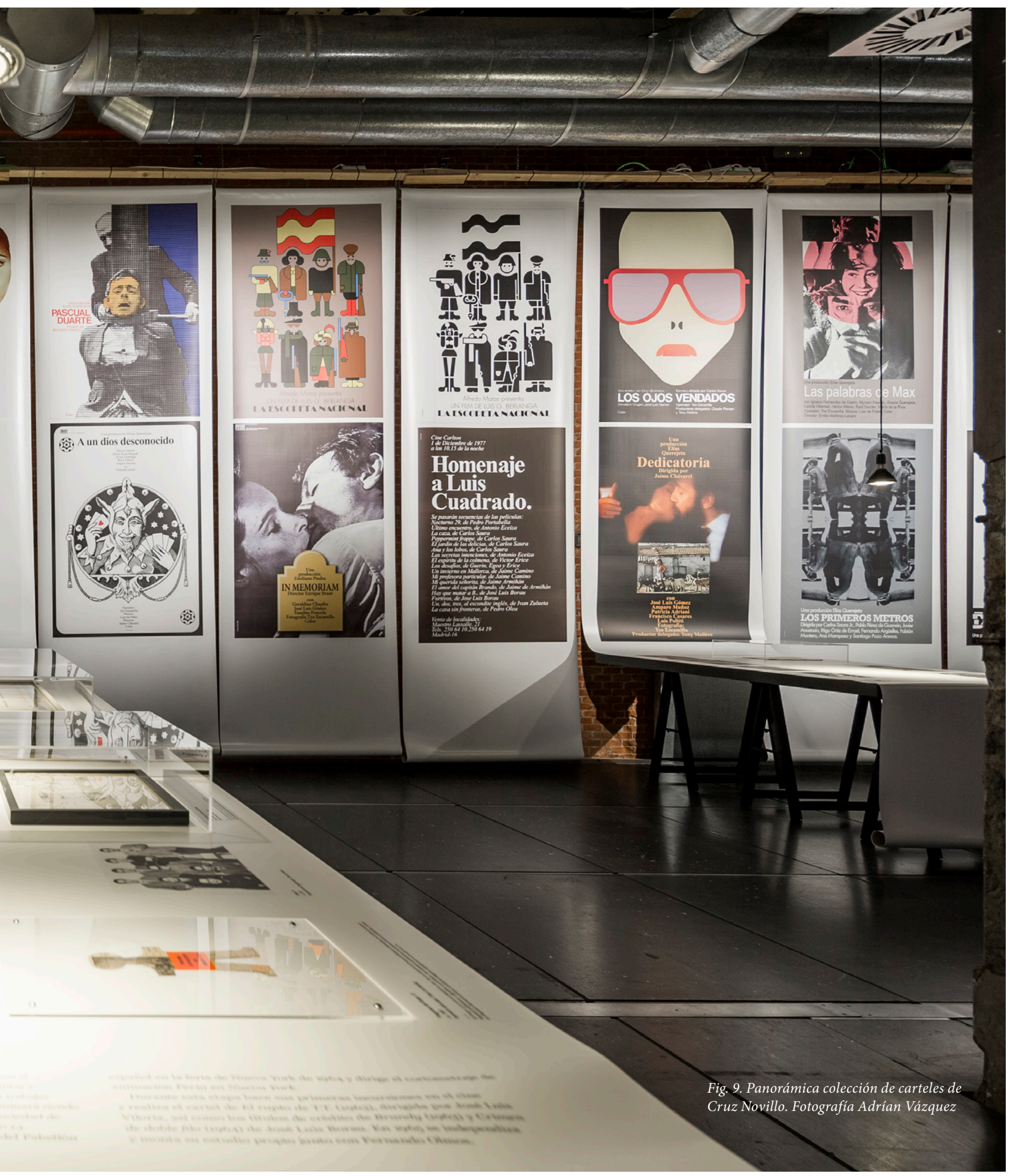




\section{Etapa 3. Elías Querejeta y una generación de creadores}

Elías Querejeta será el productor de referencia de un cine de autor y sello de producciones de calidad durante varias décadas. Funda su productora en 1963 y reúne en sus filas a nuevos directores y técnicos del entorno de la EOC. Entre los primeros destaca la colaboración con Carlos Saura en una decena de películas y otros directores como Antxon Eceiza, Víctor Erice, Basilio Martín Patino, Jaime Chávarri o Ricardo Franco.

En el equipo técnico recurrente están Luis Cuadrado, director de fotografía; Teo Escamilla, $2^{\circ}$ operador; Pablo del Amo, montador; Primitivo Álvaro, jefe de producción y el músico Luis de Pablo.

Fig. 10. Panorámica colección de carteles de Cruz Novillo. Fotografía Adrían Vázquez

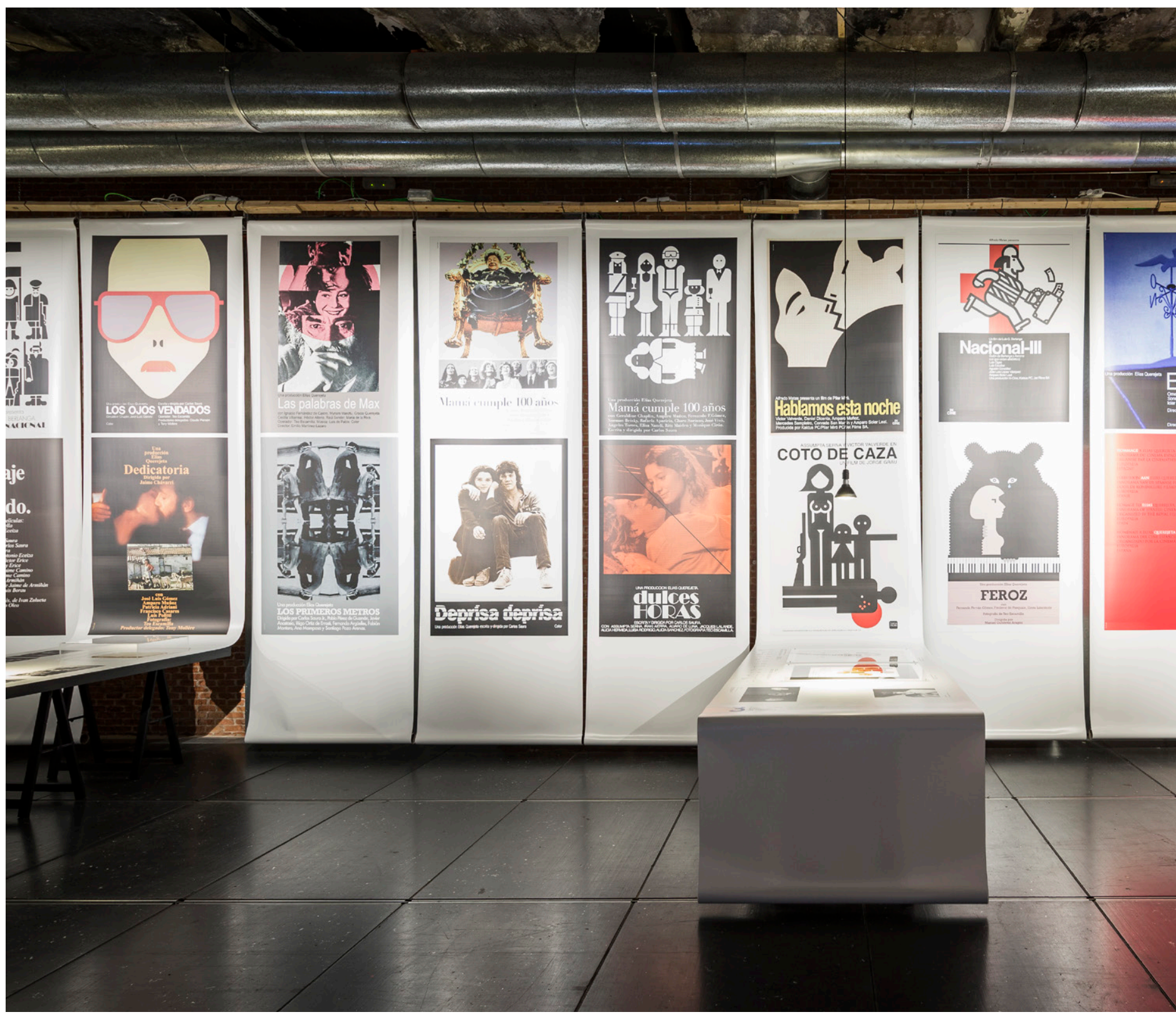




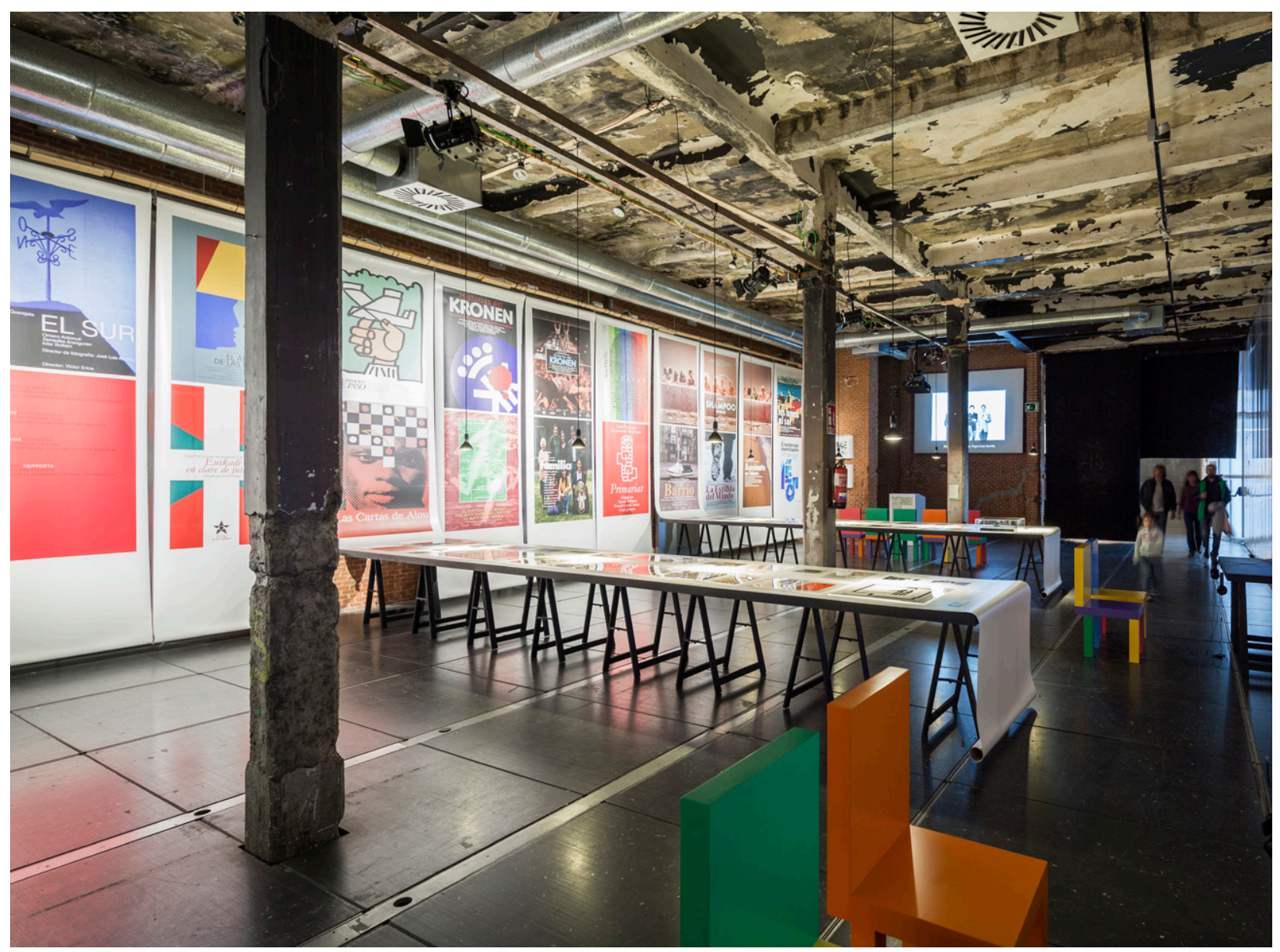

Fig. 13. Panorámica colección de carteles de Cruz Novillo. Fotografía Adrían Vázquez

\section{Etapa 5. La Llegada de la democracia}

Con la llegada de la democracia y la celebración de las primeras elecciones democráticas en mayo de 1977, en España está todo por hacer. Una época de cambios, de adaptación a una nueva realidad, en la que se suceden grandes cambios a nivel social, económico y cultural. A las producciones cinematográficas y directores consagrados, se suma una nueva generación de directores de cine con nuevas propuestas.

Cruz Novillo será el artífice de la iconografía que modernizó la imagen de instituciones públicas y compañías privadas emblemáticas de España. En el ámbito del cine continúa la fructífera colaboración con Querejeta y otros productores como Emilano Piedra, Alfredo Matas o Andrés Vicente Gómez. 

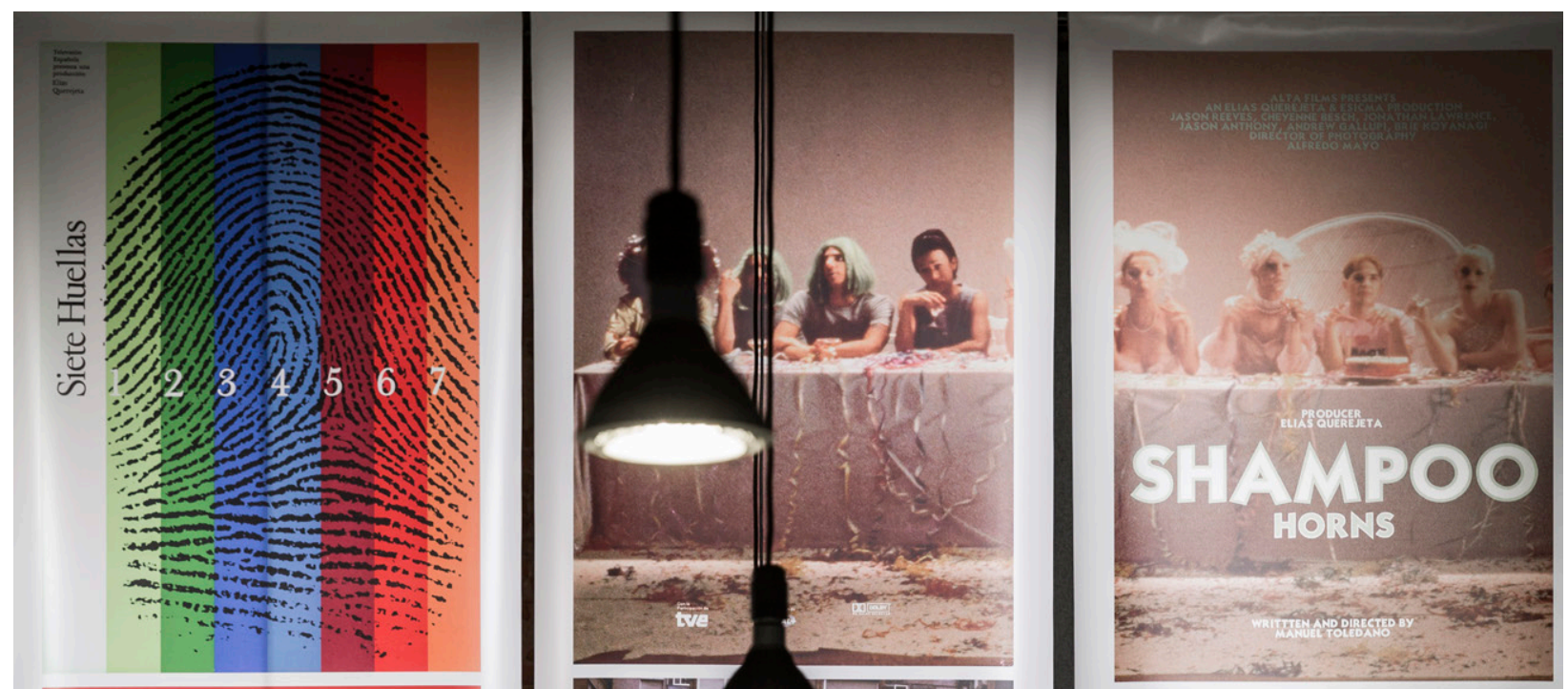

Canal Plus presenta

una producción Elias Querejeta

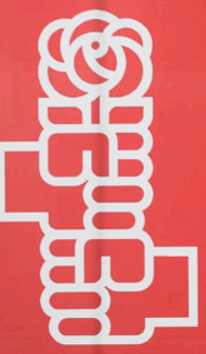

Primarias

Dirigida por

Azucena Rodriguez

Fernando León de Aranoa

Gracia Querejeta
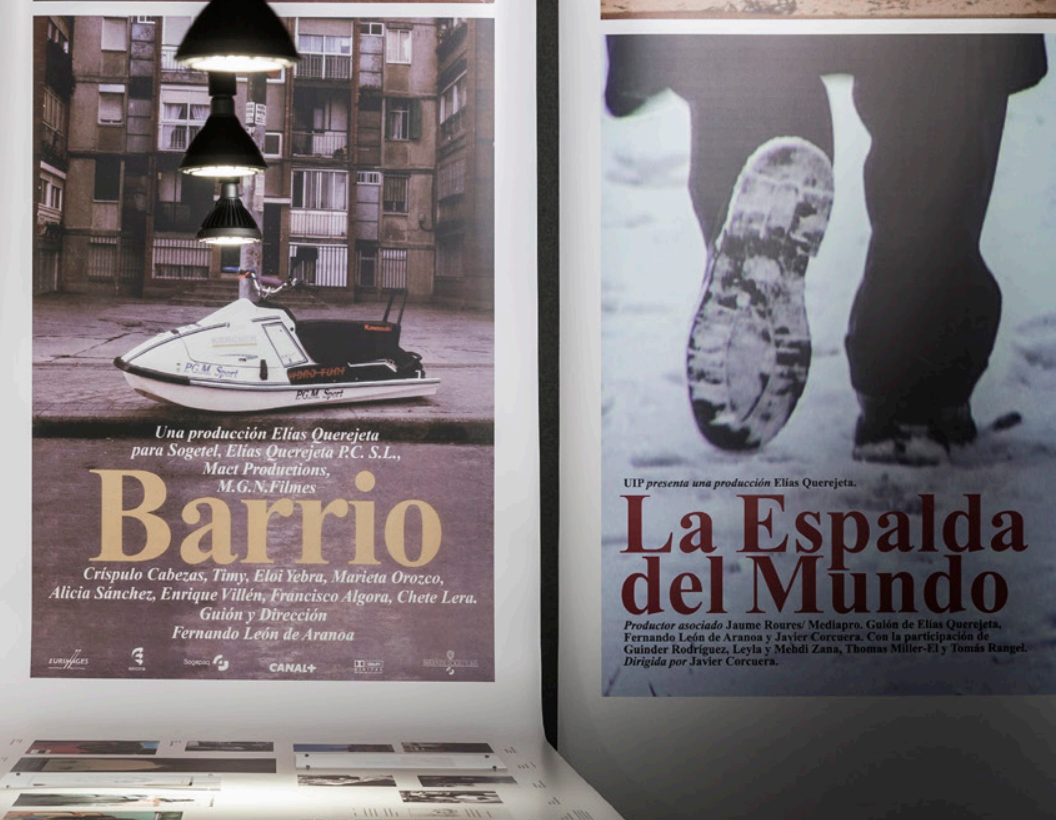

\section{deliundo}
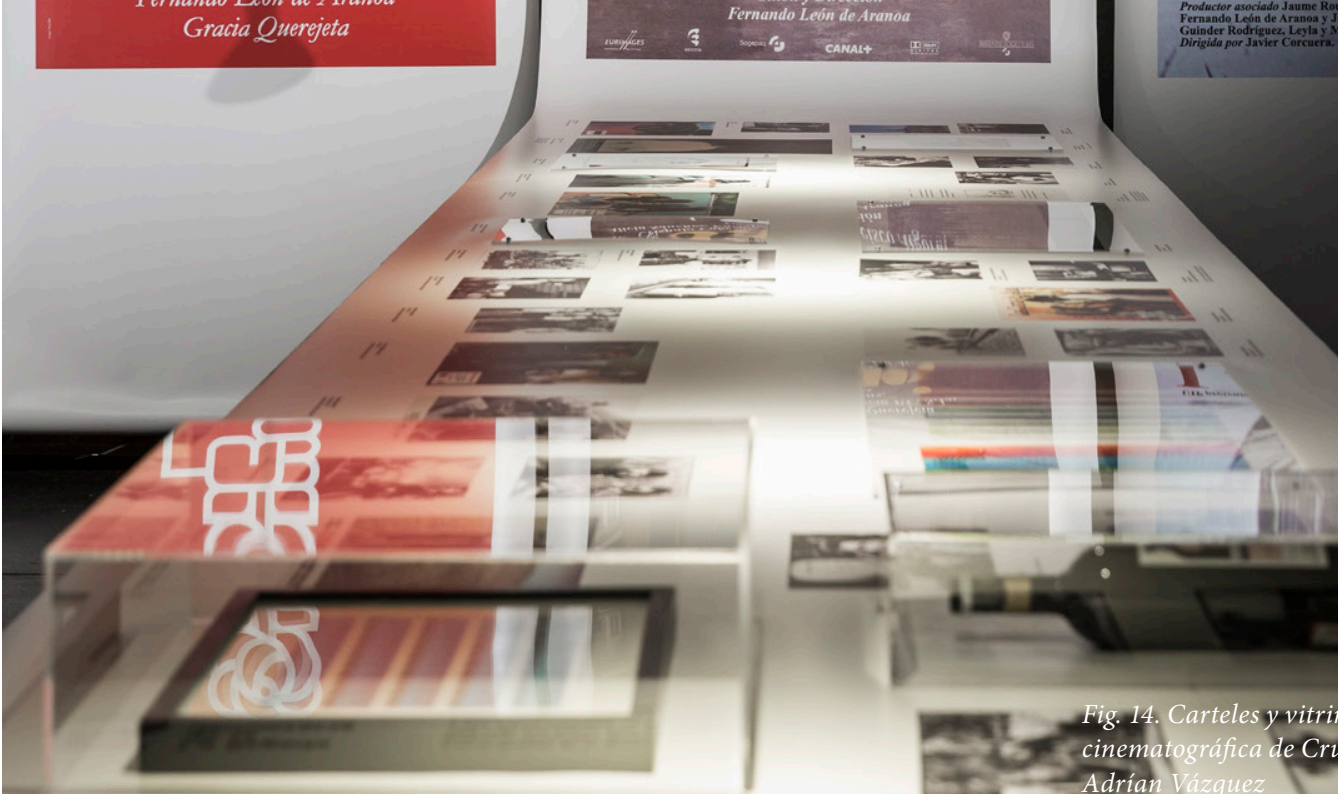


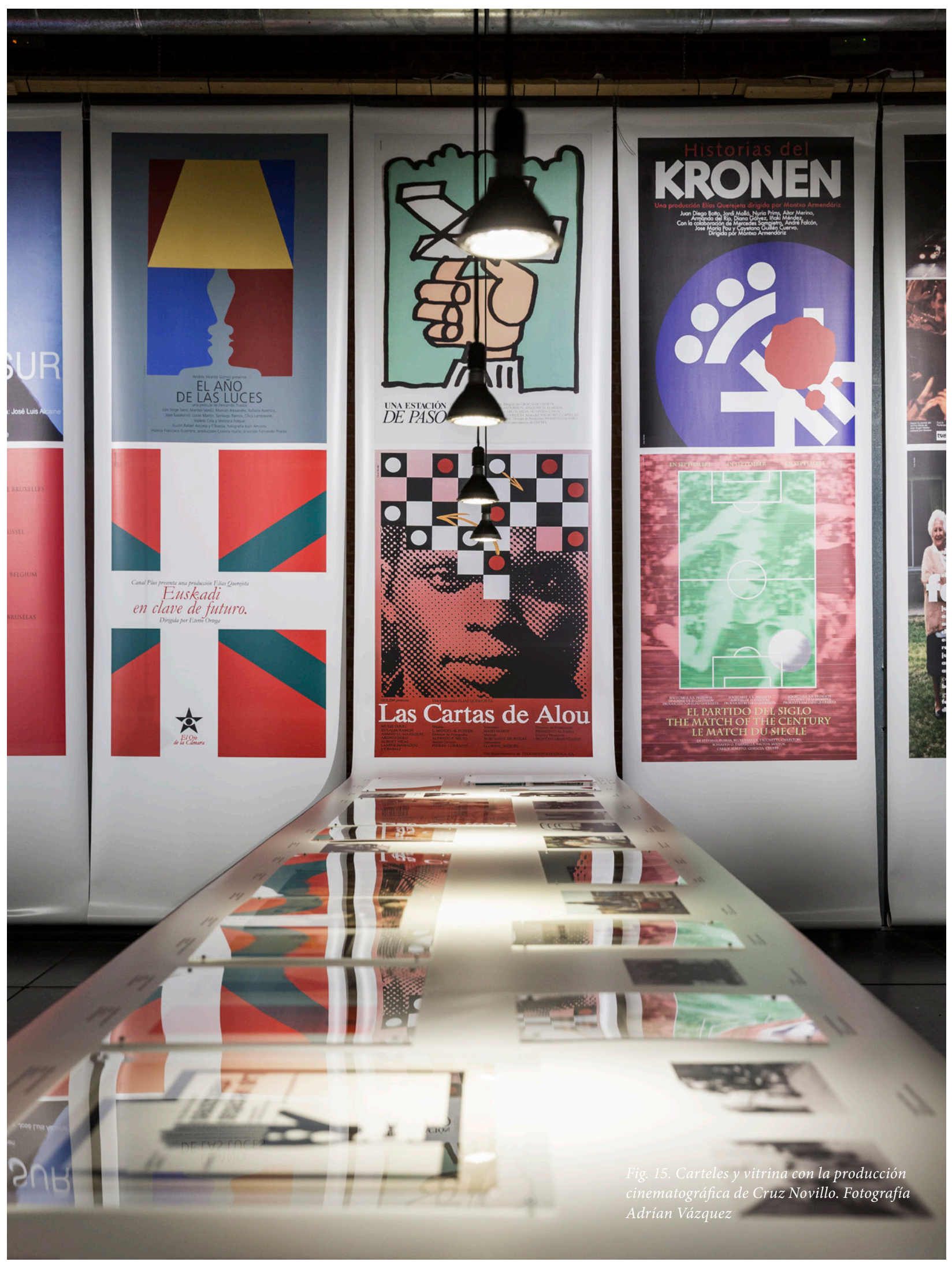




\section{El espacio}

La Central de Diseño, espacio situado en la Nave N ${ }^{0} 17$ del Centro de creación contemporánea Matadero Madrid, es la sede de DIMAD (Asociación y Fundación Diseño Madrid) donde se realizan periódicamente exposiciones emblemáticas como la Bienal Iberoamericana del Diseño, Madrid Gráfica, Producto Fresco, Complementarios, Talleres Mutantes, entre otras muchas otras actividades asociativas, formativas y divulgativas del diseño hecho en Madrid y fuera de Madrid. La Central de Diseño es pues, un lugar comprometido con la difusión del diseño y la cultura del diseño cuya arquitectura interior ha conservado el aspecto industrial de las Naves originales construidas por el arquitecto Luis Bellido en la década de 1920.

\section{El diseño expositivo}

El diseño expositivo corrió a cargo de Mariano Martín del estudio Mariano.El carácter marcadamente industrial del espacio, donde la intervención ha sido mínima, hace de la Central de Diseño un espacio con cierta complejidad para hacer una exposición dominada fundamentalmente por la gráfica, donde las

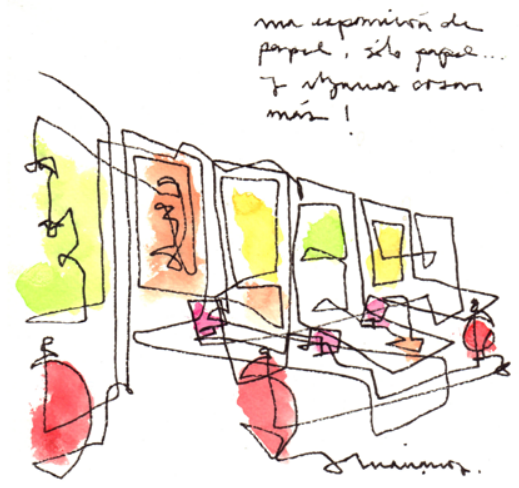

Fig. 16. Croquis de la exposición. Tinta y acuarela Mariano Martín

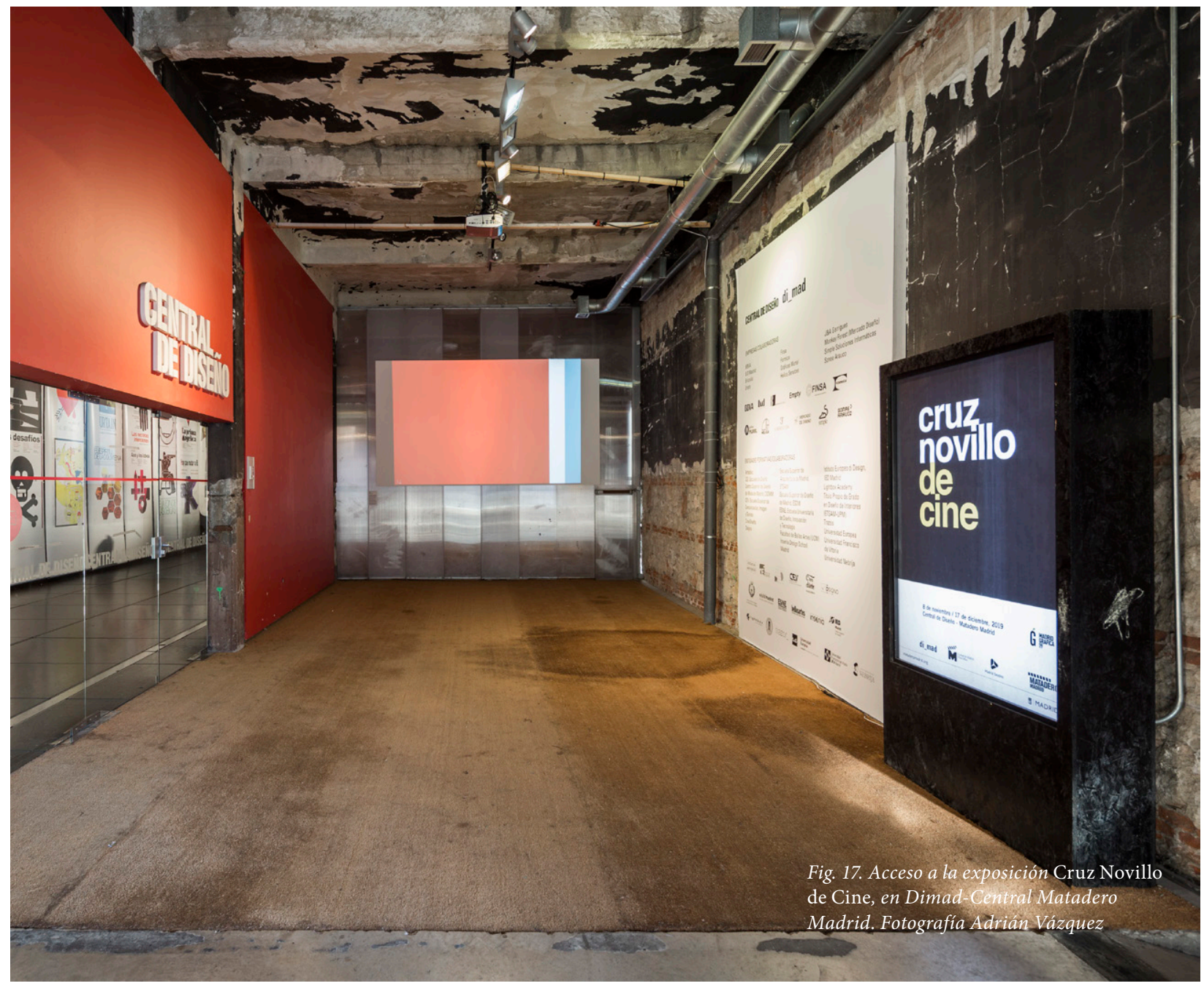




piezas expuestas corren el riesgo de ser anuladas por la propia fuerza de los materiales constructivos. Por esa razón se decidió sobredimensionar las medidas de los carteles de Pepe Cruz Novillo, piezas alrededor de los cuales gira el resto de la exposición.

Para el estudio Mariano fue un verdadero reto encontrar el lenguaje expositivo justo donde debían convivir la cartelería y el resto de las piezas gráficas y audiovisuales.

El papel es tratado como actor principal, como herramienta clara de una época, un material que poco a poco va cayendo en desuso, un único sistema constructivo..., todo ello para fijar la atención en lo importante: los maravillosos carteles que Pepe Cruz Novillo supo hacer de una forma única. Enormes rollos ploteados que a veces son pared y otras mesa que de una forma actual nos acerca a otra época en la que todo se hacía a mano, donde queda claro que no se pretende replicar sino explicar el fructífero trabajo de una época y que la falta de medios no fue razón para no dar la máxima calidad. Así, los carteles en vertical en la misma hoja, se convierten en fotogramas de las películas en horizontal y sólo se interrumpen por ciertas piezas originales que, protegidas como se merecen, aparecen como pequeños relieves sobre las grandes mesas.

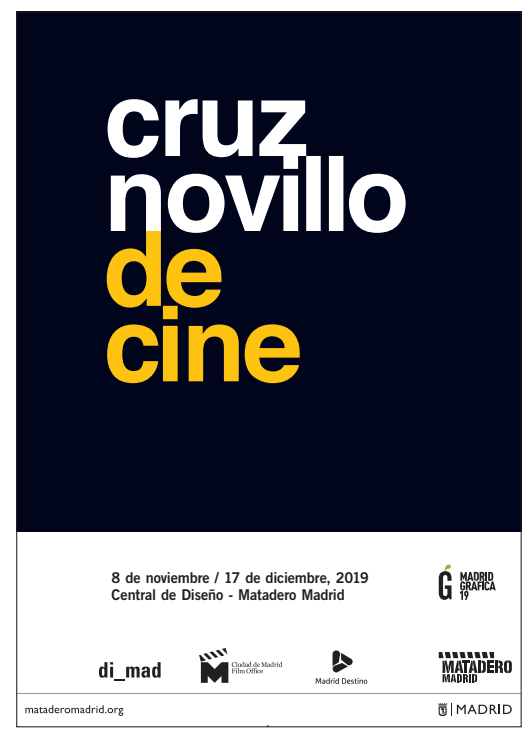

Fig. 20. Cartel de la exposición. Diseño Turégano

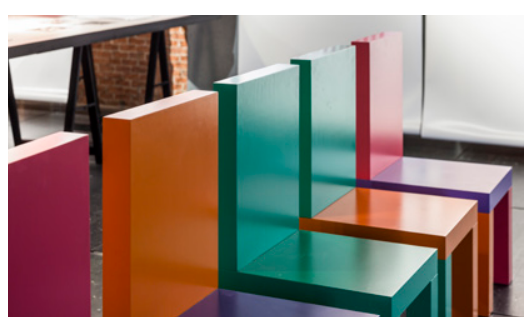

Fig. 21. Sillas del Diagrama Hexafónico. Pepe Cruz Novillo, 2007. Pintura lacada sobre madera (Cortesía de Galería Fernando Pradilla)

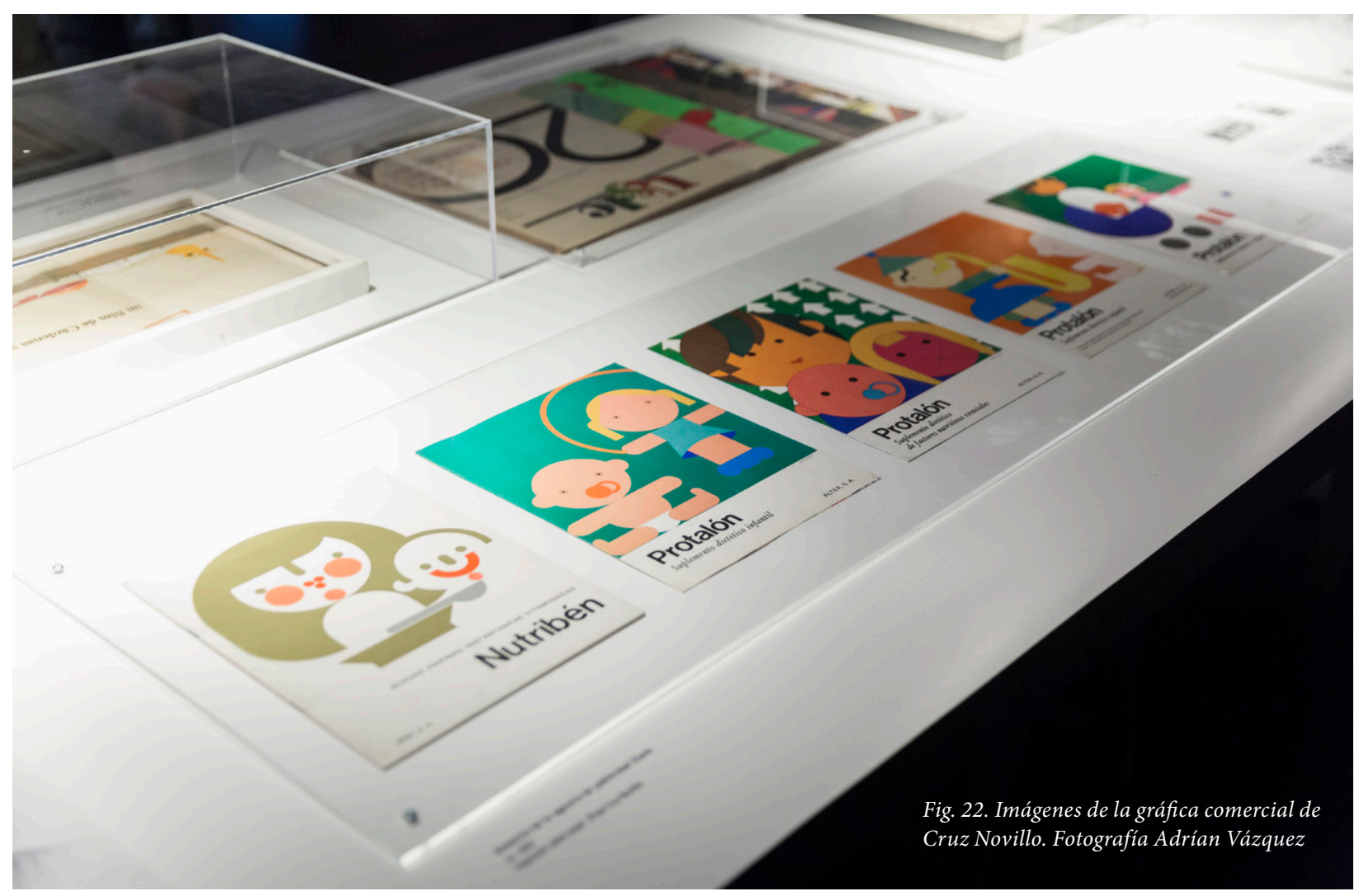


Fig. 23. Primer plano espacio proyecciones documentales

Fig. 24. Guión El Viejecito. Manuel Summers, 1960. Papel mecanografiado (Familia Summers)
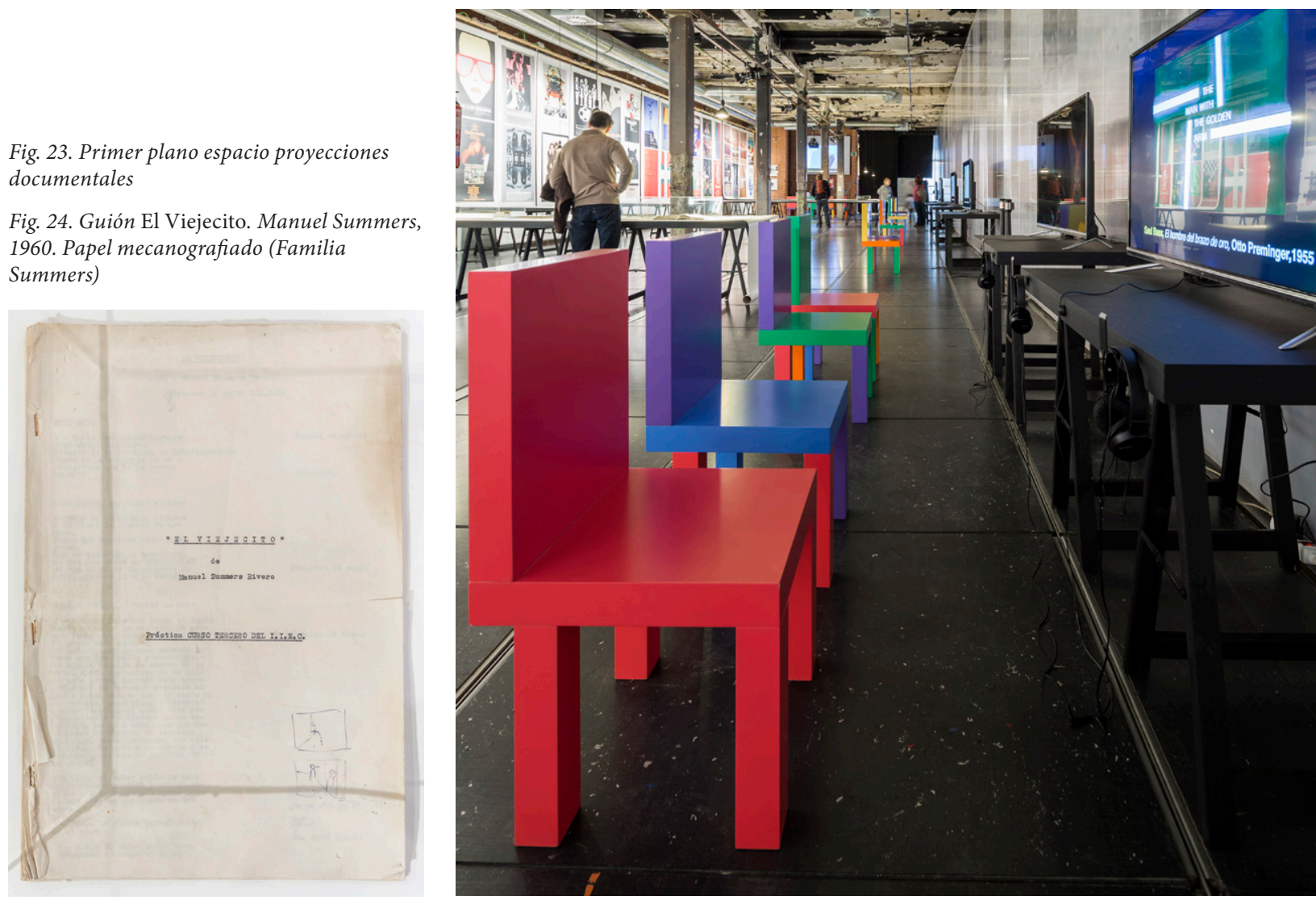

\section{Diseño de la imagen}

El diseño de la imagen gráfica corrió a cargo de Roberto Turégano, reconocido diseñador gráfico que optó por la sobriedad y la elegancia en las piezas que se desarrollaron. Como anteriormente explicamos, la mayor parte de la exposición se imprimió en papel continuo de techo a suelo en algunos casos y de techo a suelo pasando por las cinco grandes mesas temáticas donde, no solo se imprimieron los carteles, fotografías de rodaje, foto-cromos de películas, pies de foto, etc.; sino que debían conservar espacios vacíos para «las piezas originales» expuestas con exactitud. La aplicación gráfica la realizó Antonio Pita con una especial meticulosidad.

\section{Documentación}

Noa Losada, experta documentalista en temas de arte, cine y diseño, ha pilotado con gran destreza y profesionalidad la ingente labor de documentación necesaria para entrecruzar las variables narrativas del comisariado. Mucho del material visionado y recopilado no ha sido expuesto para salvaguardar la consistencia en el discurso conceptual y expositivo.

Nuestro agradecimiento a todas las personas, archivos, empresas e instituciones que han colaborado:

Academia de cine / Academia de publicidad / Archivo General de la Universidad de Navarra / Brace Consulting Management / Centro de documentación 


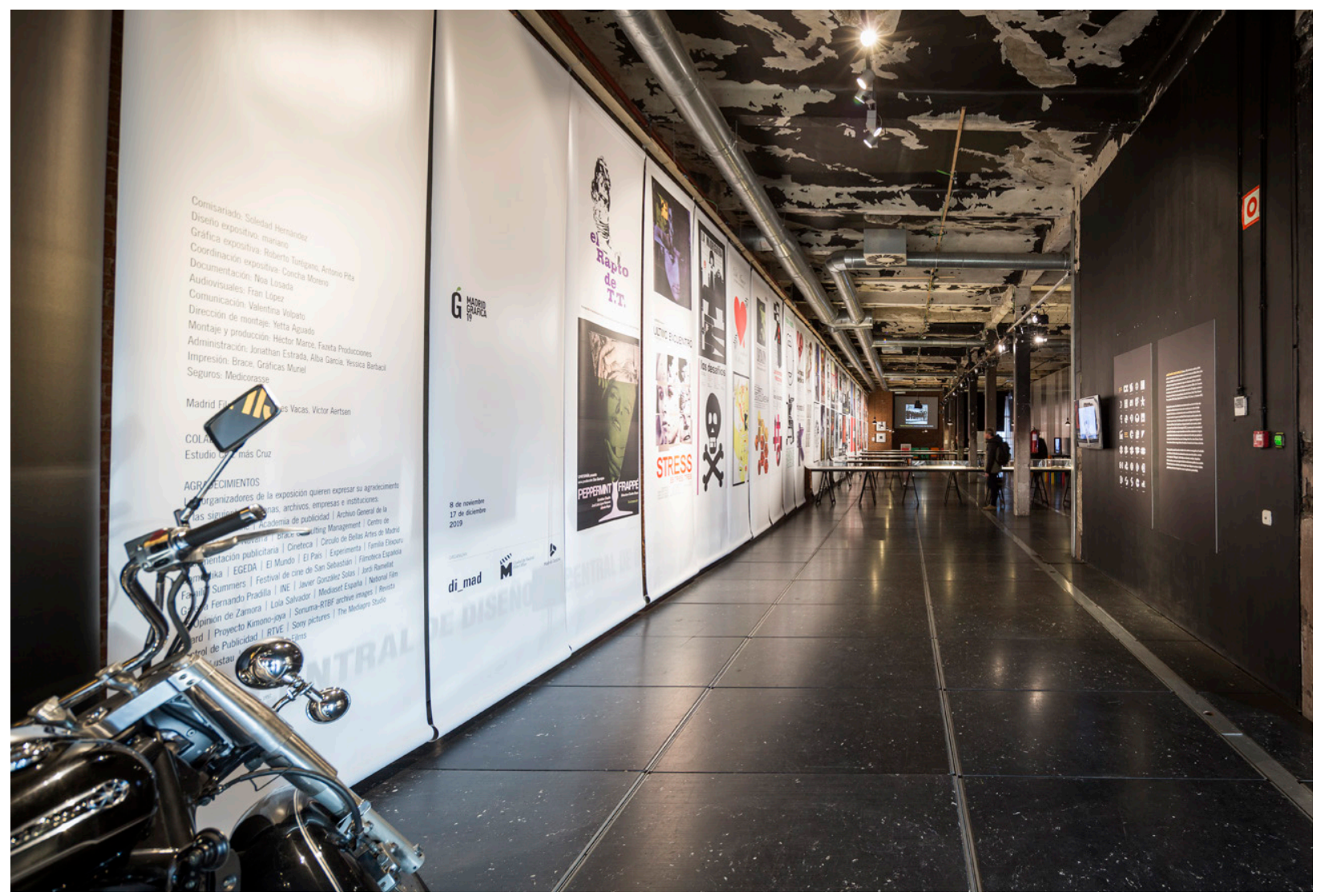

publicitaria, Cineteca / Círculo de Bellas Artes de Madrid / Domestika / EGEDA / El Mundo / El País / Experimenta / Familia Eléxpuru / Familia Summers / Festival de cine de San Sebastián / Filmoteca Española / INE / Javier González Solas / Jordi Ramellat / La Opinión de Zamora / Lola Salvador / Mediaset España / National Film Board / Proyecto Kimono-joya (Setdart subastas) / Sonuma-RTBF Archive Images / Revista Control de Publicidad / RTVE / Sony Pictures / The Mediapro Studio / Video Mercury Films / Estudio Cruz+Cruz por la cesión de material inédito e imprescindible para comprender la figura de Pepe Cruz Novillo.

\section{Piezas Audiovisuales}

Fran López, del equipo de Fazeta Producciones, encargados del montaje expositivo, convirtió los audiovisuales en pequeñas piezas exquisitas.

A través de los audiovisuales el espectador pudo disfrutar de secuencias emblemáticas del cine dirigidas por los cineastas para las cuales Pepe Cruz Novillo realizó los carteles. Rinden homenaje a todo un movimiento de directores, ampliamente reconocidos en festivales nacionales e internacionales, como Carlos Saura, Luis G. Berlanga, Víctor Erice, Jaime Chávarri, Ricardo Franco, Manuel Gutiérrez Aragón, Monxo Armendariz o Fernándo León de Aranoa entre otros.

Entrevistas, documentales, reportajes, etcétera, dan continuidad expresiva y emocional al conjunto de la exposición y resumen toda la etapa de nuestra
Fig. 25. Acceso a la exposición Cruz Novillo de Cine. Fotografía Adrián Vázquez 


\section{El hombre que diseñó España}

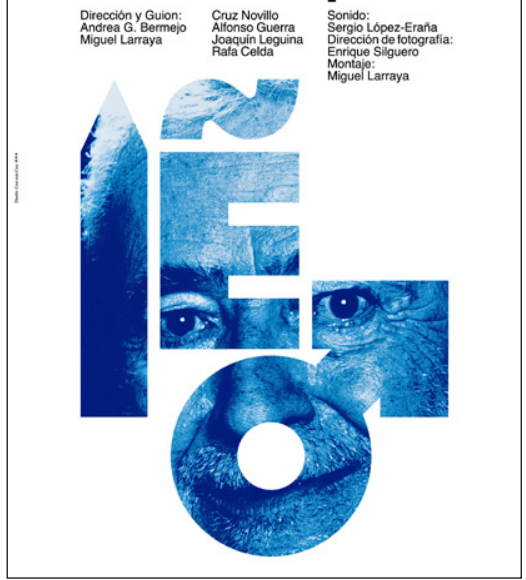

cultura en la que vivió el joven Cruz Novillo y de la que forma parte hasta nuestros días.

\section{Gestión}

Esta exposición no hubiera sido posible sin el amplio conocimiento e implicación de Ángeles Vacas en la coordinación y Víctor Aertsen en la comunicación de la Ciudad de Madrid Film Office.

Por otro lado, hay que resaltar la gran experiencia del equipo de DIMAD, encabezado por Concha Moreno en la gestión de grandes exposiciones y eventos en La Central de Diseño Matadero Madrid.

\section{Actividades Paralelas. Cineteca Matadero Madrid}

Proyección de la película El hombre que diseñó España. Guion y dirección Andrea G. Bermejo, Miguel Larraya. 2019.

Mesa redonda sobre la figura de Pepe Cruz Novillo con Andrea G. Bermejo, Miguel Larraya y Pepe Cruz Jr.

\section{Créditos}

Comisariado: Soledad Hernández

Diseño expositivo: Mariano

Gráfica expositiva: Roberto Turégano, Antonio Pita

Coordinación expositiva: Concha Moreno

Documentación: Noa Losada

Audiovisuales: Fran López

Comunicación: Valentina Volpato

Dirección de montaje: Yetta Aguado

Montaje y producción: Héctor Marce, Fazeta Producciones

Administración: Jonathan Estrada, Alba García, Yessica Barbacil 